\title{
HUBUNGAN PARITAS DENGAN KEJADIAN HIPEREMESIS GRAVIDARUM PADA IBU HAMIL DI RS MUHAMMADIYAH PALEMBANG TAHUN 2018
}

\author{
Nelly Mariyam, Idha Budiarti \\ STIK Siti Khadijah Palembang
}

Informasi Artikel :

Diterima : $\quad$ Maret 2019

Disetujui : Juni 2019

*Korespondensi Penulis :

Nellymariyam88@gmail.com

\begin{abstract}
A B S T R A K
Tujuan dari penelitian ini adalah diketahuinya hubungan paritas dengan kejadian hiperemesis gravidarum pada ibu hamil di RS Muhammadiyah Palembang Tahun 2018. Penelitian ini menggunakan desain penelitian cross sectional. Besar sampelnya adalah 35 responden diambil dengan teknik total sampling. Hasil penelitian menunjukkan bahwa kelompok primipara yang mengalami hiperemesis gravidarum tingkatan pertama 0 responden $(0 \%)$, hiperemesis gravidarum tingkatan kedua 11 responden $(44,0 \%)$ dan hiperemesis gravidarum tingkatan ketiga sebanyak 14 responden $(56,0 \%)$. Pada kelompok multipara jumlah ibu yang megalami hiperemesis gravidarum tingkatan pertama 2 responden $(20,0 \%)$, hiperemesis gravidarum tingkatan kedua 3 responden $(30,0 \%)$, dan hiperemesis gravidarum tingkatan ketiga sebanyak 5 responden $(50,0 \%)$. Terdapat hubungan yang bermakna antara paritas dengan kejadian hiperemesis gravidarum pada ibu hamil di RS Muhammadiyah Palembang tahun 2018 ( $p$ value $=0,067<\alpha=0,05$ ). Berdasarkan hasil penelitian ini disarankan kepada petugas kesehatan untuk melakukan deteksi dini bagi ibu yang diidentifikasi memiliki faktor risiko hiperemesis melalui konseling dan pelayanan KIA.
\end{abstract}

Kata Kunci : : Paritas, Kejadian Hiperemesis Gravidarum

\section{ABSTRACT}

The aim of this study is to know the correlation between parity and hyperemesis gravidarum to pregnant mothers at Muhammadiyah Hospital Palembang 2018. The method of this study is cross sectional research design. The sample of study was 35 respondents taken with total sampling technique. The result of study showed that primipara group having hyperemesis gravidarum in the first level 0 respondent (0\%), hyperemesis gravidarum second level 11 respondents $(44,0 \%)$ and hyperemesis gravidarum third level 14 respondents $(56,0 \%)$. In the multiparous group, the number of mothers with hyperemesis gravidarum was 2 respondents (20.0\%), hyperemesis gravidarum second level 3 respondents (30.0\%), and hyperemesis gravidarum third level of 5 respondents (50.0\%). There was a significant correlation between parity and hyperemesis gravidarum occurrence in pregnant mothers at Muhammadiyah Hospital Palembang 2018 ( $p$ value $=0,067<\alpha=0,05)$. Based on the results of this study it is suggested to health workers to perform early detection for mothers who are identified to have hyperemesis risk factors through counseling and KIA services.

Keywords $\quad$ : Parity, Hypremesis Gravidarum 


\section{PENDAHULUAN}

Pelayanan antenatal merupakan pelayanan yang diterima wanita selama kehamilan dan sangat penting dalam membantu memastikan bahwa ibu dan janin selamat serta tidak ada komplikasi pada kehamilan dan persalinan. Salah satu komplikasi kehamilan pada trimester I adalah hiperemsis gravidarum. Hiperemesis Gravidarum adalah mual muntah berlebihan sehingga menimbulkan gangguan aktivitas sehari-hari. Hiperemesis gravidarum bila terjadi terus menerus dapat menyebabkan dehidrasi sehingga cadangan karbohidrat dan lemak habis terpakai untuk keperluan energi. Mual dan muntah yang terus menerus tanpa pengobatan dapat menimbulkan gangguan tumbuh kembang janin dalam rahim. Pada tingkat yang lebih berat hiperemesis dapat mengancam jiwa ibu dan janin sehingga pengobatan perlu segera diberikan (Winkjosastro, 2005).

Hiperemesis gravidarum terjadi $60-80 \%$ pada primigravida dan $40-60 \%$ pada multigravida (Arief, 2009).Hiperemesis gravidarum lebih sering dialami oleh primigravida daripada multigravida, hal ini berhubungan dengan tingkat kestresan dan usia si ibu saat mengalami kehamilan pertama (Nining, 2009). Sedangkan multigravida yang mengalami hiperemesis gravidarum biasanya terkait dengan riwayat kehamilan pertama, kurangnya pengalaman pada kehamilan pertama dan tingkat stres yang tinggi pada saat menghadapi kehamilan sehingga menimbulkan resiko terjadinya hiperemesis gravidarum (Saifuddin, 2010).

Pada tahun 2014 jumlah ibu hamil yang tercatat dalam rekam medik RS Muhammadiyah Palembang sebanyak 3.784 orang dan yang mengalami hiperemesis gravidarum sebanyak 57 orang $(1,34 \%)$, pada tahun 2015 jumlah ibu hamil yang tercatat dalam rekam medik RS Muhammadiyah Palembang sebanyak 3.910 orang dan yang mengalami hiperemesis gravidarum sebanyak 51 orang $(1,30 \%)$ dan pada tahun 2016 jumlah ibu hamil yang tercatat dalam rekam medik RS Muhammadiyah Palembang sebanyak 3.041 orang dan yang mengalami hiperemesis gravidarum sebanyak 35 orang $(1,15 \%)$. Menurut data dari bulan Januari-Juni di RS Muhammadiyah Palembang tahun 2018, jumlah ibu hamil yang mengalami hiperemesis gravidarum sebanyak 24 orang.

\section{METODE PENELITIAN}

Jenis penelitian ini adalah kuantitatif dengan metode analitik dengan desain penelitian cross sectional. Populasi dalam penelitian ini adalah seluruh ibu hamil dengan hiperemesis gravidrum yang tercatat dalam rekam medik RS Muhammadiyah Palembang tahun 2016 sebanyak 35 orang. sampelnya adalah ibu hamil yang mengalami hiperemesis gravidarum di RS Muhammadiyah Palembang tahun 2018 sebanyak 35 responden, teknik pengambilan sampel menggunakan total sampling.

Data primer dari penelitian ini meliputi paritas dan kejadian hiperemesis gravidarum yang diperoleh melalui observasi rekam medik pasien dengan menggunakan lembar checklist.

Data akan dianalisis dengan menggunakan analisis univariat dan bivariat. Analisis univariat untuk melihat distribusi frekuensi dari masingmasing kategori variabel dan analisis bivariat bertujuan untuk melihat hubungan antara variabel independen (paritas) dan variabel dependen (kejadian hiperemesis gravidarum) dengan menggunakan uji statistik chi square test.

\section{HASIL PENELITIAN}

\section{Status Gizi}

Tabel 1. Distribusi Frekuensi Paritas

\begin{tabular}{|c|c|c|c|}
\hline No. & Paritas & n & $\%$ \\
\hline 1. & Primipara & 25 & 71,4 \\
\hline 2. & Multipara & 10 & 28,6 \\
\hline & Jumlah & 35 & 100 \\
\hline
\end{tabular}

2. Kejadian Hiperemesis Gravidarum

Tabel 2. Distribusi Frekuensi Kejadian Hiperemesis Gravidarum

\begin{tabular}{cccc}
\hline No. & $\begin{array}{c}\text { Kejadian Hiperemesis } \\
\text { Gravidarum }\end{array}$ & n & \% \\
\hline 1. & HEG Tingkatan pertama & 2 & 5,7 \\
\hline 2. & HEG Tingkatan Kedua & 14 & 40 \\
\hline 3. & HEG Tingkatan Ketiga & 19 & 54,3 \\
\hline & Jumlah & 35 & 100 \\
\hline
\end{tabular}




\section{Hubungan Paritas dengan Kejadian Hiperemesis Gravidarum}

\begin{tabular}{|c|c|c|c|c|c|c|c|c|c|c|}
\hline \multirow{3}{*}{$\begin{array}{l}\text { N } \\
\text { o. }\end{array}$} & \multirow{3}{*}{ Paritas } & \multicolumn{6}{|c|}{$\begin{array}{c}\text { Kejadian Hiperemesis } \\
\text { Gravidarum }\end{array}$} & \multirow{2}{*}{\multicolumn{2}{|c|}{ Total }} & \multirow{3}{*}{$\begin{array}{c}p \\
\text { value }\end{array}$} \\
\hline & & \multicolumn{2}{|c|}{$\begin{array}{r}\text { Tingkat } \\
\text { Pertama }\end{array}$} & \multicolumn{2}{|c|}{$\begin{array}{l}\text { Tingkat } \\
\text { Kedua }\end{array}$} & \multicolumn{2}{|c|}{$\begin{array}{l}\text { Tingkat } \\
\text { Ketiga }\end{array}$} & & & \\
\hline & & $\mathbf{n}$ & $\%$ & $\mathbf{n}$ & $\%$ & $\mathbf{n}$ & $\%$ & $\mathbf{N}$ & $\%$ & \\
\hline 1. & Primipara & 0 & 0 & 11 & 44 & 14 & 56 & 25 & 100 & \\
\hline 2. & Multipara & 2 & 20 & 3 & 30 & 5 & 50 & 10 & 100 & 0,067 \\
\hline & jumlah & 2 & 5,7 & 14 & 40 & 19 & 54,3 & 35 & 100 & \\
\hline
\end{tabular}

\section{PEMBAHASAN}

\section{Paritas}

Hasil dari penelitian di RS Muhammadiyah Palembang diperoleh data bahwa distribusi frekuensi responden dengan kategori hiperemesis gravidarum pada paritas primipara sebanyak 25 orang $(71,4 \%)$ dan multipara 10 orang $(28,6 \%)$.

Menurut Manuaba (2010) Sekitar 60-80 $\%$ primigravida dan $40-60 \%$ multigravida mengalami mual dan muntah, namun gejala ini menjadi lebih berat hanya pada 1 dari 1.000 kehamilan, Walaupun kebanyakan kasus ringan dan dengan seiring waktu, satu dari setiap 1000 wanita hamil akan menjalani rawat inap, kondisi ini sering terjadi pada wanita primigravida dan cenderung terjadi lagi pada kehamilan berikutnya.

Winkjosastro, (2007) mengungkapkan bahwa ibu primigravida belum mampu beradaptasi terhadap hormon estrogen dan khorionik gonadotropin. Peningkatan hormon ini membuat kadar asam lambung meningkat, hingga muncullah keluhan rasa mual. Keluhan ini biasanya muncul di pagi hari saat perut ibu dalam keadaan kosong dan terjadi peningkatan asam lambung.

Berdasarkan teori dan hasil penelitian diatas dapat disimpulkan bahwa ibu dengan paritas primipara lebih banyak mengalami hiperemesis gravidarum dibandingkan ibu dengan paritas multipara.

\section{Kejadian Hiperemesis Gravidarum}

Hasil dari penelitian di RS Muhammadiyah Palembang diperoleh data bahwa distribusi frekuensi responden dengan kategori hiperemesis gravidarum tingkatan pertama sejumlah 2 responden $\quad(5,7 \%)$, kategori hiperemesis gravidarum tingkatan kedua sejumlah 14 responden $(40,0 \%)$ dan kategori hiperemesis gravidarum tingkatan ketiga sejumlah 19 responden $(54,3 \%)$.

Hiperemesis gravidarum adalah mual dan muntah berlebihan selama masa hamil muntah yang membahayakan ini dibedakan dari morning sickness normal yang umumnya dialami wanita hamil karena intensitasnya yang melebihi muntah normal dan berlansung selama trimester pertama kehamilan (Varney, 2007).

Menurut Manuaba (2010) gambaran gejala hiperemesis gravidarum secara klinis dapat dibagi menjadi tiga tingkatan yaitu:

Hiperemesis gravidarum tingkatan pertama : Muntah berlangsung terus, makan berkurang, berat badan menurun, kulit dehidrasi-tonus lemah, nyeri didaerah epigastrium, tekanan darah turun dan nadi meningkat, lidah kering dan mata tampak cekung

Hiperemesis gravidarum tingkatan kedua : Penderita tampak lebih lemah, gejala dehidrasi makin tampak mata cekung, turgor kulit makin kurang, lidah kering dan kotor, tekanan darah turun, nadi meningkat, berat badan makin menurun, mata ikteris, gejala hemokosentrasi makin tampak, urin berkurang, terjadi gangguan buang air besar, mulai tampak gejala gangguan kesadaran menjadi apatis dan napas berbau aseton.

Hiperemesis gravidarum tingkatan ketiga : Muntah berkurang, keadaan umum wanita hamil makin menurun, tekanan darah turun, nadi meningkat dan suhu naik, keadaan dehidrasi makin jelas, gangguan fatal hati terjadi dengan manifestasi ikterus, gangguan kesadaran dalam bentuk samnolen sampai koma, tekanan darah turun, nadi meningkat dan berat badan makin menurun.

Berdasarkan hasil penelitian diatas dapat disimpulkan bahwa ibu dengan kategori hiperemesis gravidarum tingkatan ketiga lebih banyak dibandingkan dengan kategori hiperemesis tingkatan kedua dan pertama.

\section{Hubungan Paritas dengan Kejadian Hipermemesis Gravidarum}

Pada penelitian ini dibagi menjadi dua kategori, yaitu primipara (bila paritas ibu 1 anak) dan multipara (bila paritas ibu 2-4 anak) sedangkan kejadian hiperemesis gravidarum 
menjadi 2 kategori, yaitu hiperemesis gravidarum dan tidak hiperemesis gravidarum.

Hasil analisis univariat menunjukkan bahwa jumlah responden dengan kategori primipara lebih banyak yaitu 25 responden $(71,4 \%)$ dibandingkan jumlah ibu dengan multipara yaitu 10 responden $(28,6 \%)$.

Hasil analisis bivariat menunjukkan pada kelompok primipara yang mengalami hiperemesis gravidarum tingkatan ketiga lebih banyak yaitu 14 responden $(56,0 \%)$ dibandingkan yang mengalami hiperemesis gravidarum tingkatan kedua 11 responden $(44,0 \%)$ dan hiperemesis gravidarum tingkatan pertama 0 responden $(0 \%)$. Sedangkan, pada kelompok multipara jumlah ibu yang megalami kejadian hiperemesis gravidarum tingkatan ketiga juga lebih banyak 5 responden $(50,0 \%)$ dibandingkan yang mengalami hiperemesis gravidarum tingkatan kedua 3 responden $(30,0 \%)$ dan hiperemesis gravidarum tingkatan pertama 2 responden $(20,0 \%)$.

Hasil uji Chi-Square menunjukkan $p$ value $(0,067)<\alpha(0,05)$. Hal ini menunjukkan ada hubungan antara paritas dengan kejadian hiperemesis gravidarum pada ibu hamil di RS Muhammadiyah Palembang tahun 2016. Sehingga, hipotesis yang menyatakan ada hubungan antara paritas dengan kejadian hiperemesis gravidarum pada ibu hamil terbukti secara statistik.

Hiperemesis gravidarum adalah mual dan muntah yang tidak dapat dihentikan selama kehamilan biasanya mencapai puncaknya antara minggu kedelapan dan keduabelas dan hilang pada minggu ke dua belas (Meilia, 2010).

Menurut Wiknjosastro (2005), mual dan muntah terjadi 60\%-80\% wanita dengan kehamilan pertama (primigravida) dan $40 \%$ $60 \%$ pada wanita yang sudah pernah hamil lebih dari satu kali (multigravida). Penyebab hiperemesis gravidarum belum diketahui secara pasti. Telah diketahui ada beberapa faktor predisposisi untuk terjadinya hiperemesis gravidarum, yaitu primigravida (kehamilan pertama).

Menurut Neil-Rose (2007), Tiran (2008), Proverawati (2009) mayoritasibuhamil yang mengalami Hiperemesis Gravidarum terjadi padaprimigravida, halini dikarenakan sebagian kecil ibu primigravida belum mampu beradaptasi dengan hormon (progesteron, estrogen, dan Human Chorionic Gonadotropin (HCG)).

Perasaan mual adalah akibat dari kadar estrogen meningkat, oleh karena itu keluhan ini terjadi pada trimester pertama mungkin berasal dari sistem syaraf atau akibat kekurangan pengosongan lambung (Winkjosastro, 2005: 276).

Hasil penelitian ini sejalan dengan penelitianMuliana (2012), dengan judulHubungan Umur Dan Paritas Ibu Dengan Kejadian HiperemesisGravidarum Di Rumah Sakit UmumPusat Dr. Mohammad Hoesin Palembang Tahun 2011.Hasil pengujian statistik dengan menggunakan Chi-Square menunjukkan ada hubungan yang bermakna antara paritas ibu dengan kejadian hiperemesis gravidarum, dimana $p$ value $(0,000)<\alpha$ $(0,05)$. Sehingga hipotesis yang menyatakan ada hubungan antara paritas ibu dengan kejadian hiperemesis gravidarum terbukti secara statistik.

Hasil penelitian ini juga sejalan dengan penelitian Puriati \& Misbah (2014), dengan judul Hubungan Paritas Dan Umur Ibu Dengan Kejadian Hiperemesis Gravidarum Di RSUD Adjidarmo Rangkasbitung Tahun 2011. Hasil uji statistic dengan menggunakan Chi Square pada Alpha $=0,05$ didapatkan nilai $\mathrm{P}=0,002(\mathrm{p}<0,05)$ yang berarti bahwa secara statistic terdapat hubungan yang bermakna antara paritas ibu dengan kejadian hyperemesis gravidarum di RSUD dr. Adjidarmo Rangkasbitung tahun 2011.

Begitu pula hasil penelitian ini sejalan dengan penelitian Nurfitri (2014), dengan judul Hubungan Paritas Dengan Kejadian Hiperemesis Gravidarum Pada Ibu Hamil Di Puskesmas Purbaratu Kota Tasikmalaya Tahun 2014. Hasil uji statistik diperoleh terdapat hubungan antara paritas dengan kejadian hiperemesis gravidarum pada ibu hamil dengan $p$ value $0,004(\mathrm{p}<0,05)$ yang artinya terdapat hubungan hubungan paritas dengan kejadian hiperemsis gravidarum.

Menurut pendapat peneliti berdasarkan hasil penelitian diatas mayoritas ibu hamil yang mengalami hiperemesis gravidarum adalah ibu hamil dengan paritas primipara. Hal ini dikarenakan sebagian kecil ibu primipara belum mampu beradaptasi dengan perubahan hormonal yang mengalami peningkatan sehingga menyebabkan timbulnya rasa mual yang berlebihan dan muntah yang hebat. Peningkatan hormon 
estrogen dan progesteron menyebabkan otot polos pada sistem gastrointestinal mengalami relaksasi, hal itu mengakibatkan penurunan motilitas lambung sehingga pengosongan lambung melambat. Refleks esofagus, penurunan motilitas lambung dan penurunan sekresi dari asam hidroklorid juga berkontribusi terhadap terjadinya mual dan muntah. Selain itu HCG juga menstimulasi kelenjar tiroid yang dapat mengakibatkan mual dan muntah.

\section{KESIMPULAN}

Adapun kesimpulan dari hasil penelitian diatas adalah distribusi frekuensi dari 35 responden didapatkan responden dengan kategori primipara lebih banyak yakni sejumlah 25 responden $\quad(71,4 \%)$ jika dibandingkan dengan kategori multipara yakni sejumlah 10 responden $(28,6 \%)$, distribusi frekuensi dari 35 responden didapatkan responden dengan kategori hiperemesis gravidarum tingkatan ketiga lebih banyak yakni sejumlah 19 responden $(54,3 \%)$ jika dibandingkan dengan kategori Hiperemesis Gravidarum tingkatan pertama yakni sejumlah 2 responden $\quad(5,7 \%)$ dan ada hubunganantaraparitasdengankejadianhiperemesi sgravidarum pada ibu hamildi RS Muhammadiyah Palembang tahun 2018, $p$ value 0,067 .

\section{SARAN}

Disarankan kepada petugas kesehatan untuk melakukan deteksi dini bagi ibu yang diidentifikasi memiliki faktor risiko hiperemesis serta pencegahan terhadap hiperemesis gravidarum dengan cara memberikan konseling terhadap ibu hamil tentang kehamilan dan persalinan bahwa hal tersebut merupakan suatu proses yang fisiologik serta memberikan keyakinan bahwa mual dan muntah merupakan gejala yang fisiologi pada kehamilan muda dan akan hilang setelah kehamilan 4 bulan, dapat menjadi bahan referensi dan sebagai informasi yang bermanfaat untuk perkembangan pengetahuan tentang hiperemesis gravidarum pada ibu hamil dan dapat dilakukan penelitian lebih lanjut untuk mengungkapkan faktor-faktor yang berhubungan dengan kejadian hiperemesis gravidarum pada ibu hamil serta lebih mengembangkan dan menyempurnakan penelitian ini dan menggunakan variabel-variabel yang berbeda dengan metode yang berbeda yang berhubungan dengan hiperemesis gravidarum.

\section{DAFTAR PUSTAKA}

Arif, N. 2009. Panduan Ibu Cerdas (ASI dan Tumbuh Kembang Bayi). Yogyakarta: Medis Pressindo.

Atikah Proverawati, Siti $\quad$ Asfuah. 2009. Buku Ajar Gizi untuk Kebidanan. Nuha Medika: Yogyakarta.

Manuaba, IBG, dkk. 2008. Gawat Darurat Obstetri Ginekologi dan Obstetri Ginekologi Sosial untuk Profesi Bidan. Jakarta: EGC.

Neil, Wendy Rose. 2007. Panduan Lengkap Perawatan Kehamilan. Jakarta: Dian Rakyat.

Puriati, Ruri dan Nurul Misbah. 2014. Hubungan paritas dan umur ibu dengan kejadian hiperemesis gravidarum di rsud adjidarmo rangkasbitung tahun 2011. Jurnal Obstretika Scientia, 2 (1): 180-191

$\begin{array}{ccc}\text { Abdul } & \text { Bari. 2010. } & \text { Ilmu } \\ \begin{array}{l}\text { Kebidanan, } \\ \text { Pustaka. Sarwono Prawirohardjo. }\end{array} & \text { Bina }\end{array}$

Tiran, Denise. 2008. Mual dan muntah kehamilan. Jakarta: EGC.

Varney, Helen. 2006. Buku Ajar Asuhan Kebidanan Edisi I. Jakarta: EGC.

\begin{tabular}{|c|c|c|c|}
\hline & 2007. & Buku & Ajar Asuhan \\
\hline $\begin{array}{l}\text { Kebidanan. } \\
\text { Jakarta : EGC. }\end{array}$ & Edisi & 4 , & Volume \\
\hline $\begin{array}{l}\text { Wiknjosastro, } \\
\text { Jakarta: }\end{array}$ & $\begin{array}{l}\text { H. } 2007 . \\
\text { Yayasan }\end{array}$ & $\begin{array}{l}\text { 7. Imu } \\
\text { Bina }\end{array}$ & $\begin{array}{r}\text { Kebidanan. } \\
\text { Pustaka }\end{array}$ \\
\hline
\end{tabular}


